\title{
Effect of applying nurses driven electrolyte repletion protocol on electrolyte disturbances control among critically ill patients
}

\author{
Mohamed E. Abdelgawad*1, Nadia T. Ahmed ${ }^{1}$, Ahmed M. Elmenshawy ${ }^{2}$ \\ ${ }^{1}$ Department of Critical Care and Emergency Nursing, Faculty of Nursing, Alexandria University, Egypt \\ ${ }^{2}$ Department of Critical Care Medicine, Faculty of Medicine, Alexandria University, Egypt
}

Received: August 1, 2019

DOI: $10.5430 /$ jnep.v10n4p72
Accepted: December 22, 2019 Online Published: January 19, 2020

URL: https://doi.org/10.5430/jnep.v10n4p72

\begin{abstract}
Background and objective: Electrolyte disturbances remain a common lifesaving issue in the intensive care units. They are associated with increased morbidity and mortality. They are mostly resulted secondary to critical illness itself or associated treatment modalities. Therefore, electrolytes repletion should be done effectively and timely. This could be ensured using nurse driven protocols rather than traditional methods of repletion. These protocols are nurse initiated and collaboratively developed. They have been shown to improve patient care outcomes through the provision of high quality care. They are increasingly being used in the critical care setting. Objective: Determine the effect of applying nurses driven electrolytes repletion protocol on electrolyte disturbances control among critically ill patients.

Methods: Quasi experimental research design was used. Sixty two critically ill patients with electrolyte loss were enrolled in the study at Alexandria Main University Hospital intensive care units, Egypt. All episodes of electrolyte loss were evaluated. Repletion of electrolyte loss was done according to unit routine for the control group and nurses driven electrolytes repletion protocol for the study group. Episodes of electrolyte disturbances, adverse events and timing of repletion were evaluated.

Results: Neurological disorders represent the most encountered diagnosis. The most common cause of electrolyte loss was the use of diuretics. Furthermore, there was a highly statistical difference between the two groups as regard electrolytes levels, effectiveness and timing of replacement.

Conclusions: Application of nurses driven electrolyte repletion protocol resulted in improvement in the effectiveness and timeliness of electrolyte replacement.
\end{abstract}

Key Words: Nurse driven protocol, Electrolytes repletion, Critically ill patient

\section{INTRODUCTION}

Electrolyte disturbances have been strongly and consistently linked with increased Intensive Care Unit (ICU) stay, mechanical ventilation (MV) days, morbidities, healthcare costs and hospital mortality in Critical ill patients (CIPs). ${ }^{[1,2]}$ In relation to hypokalemia, it is manifest as neuromuscular alterations, including paralysis, weakness, and respiratory muscle weakness. The most drastic complications are cardiac dysrhythmia, especially in patients with hypertension, myocardial ischemia, or heart failure. ${ }^{[3,4]}$

As regard to hypomagnesaemia, the severe form can result in cardiac dysrhythmia known as torsade's de pointes. Also, it can result in seizures, coma, and death. It is associated with

\footnotetext{
*Correspondence: Mohamed E. Abdelgawad; Email: Mohamed.ezz@alexu.edu.eg; Address: Department of Critical Care and Emergency Nursing, Faculty of Nursing, Alexandria University, Egypt.
} 
concomitant electrolyte disturbances such as hypokalemia and hypocalcaemia. ${ }^{[5,6]}$ Regarding hypophosphatemia, it is associated with platelet dysfunction, confusion, seizures and coma; respiratory failure; cardiac dysrhythmia and cardiomyopathy. ${ }^{[7,8]}$

Thus, electrolyte disturbances should be monitored and corrected, effectively and timely. ${ }^{[2,9-11]}$ Unfortunately, there is great variability in the dosing, timing, and monitoring of electrolyte repletion by individual clinicians. ${ }^{[6,12-14]}$ By virtue of this, many institutions have implemented electrolytes replacement protocols. Numerous trials have documented the utility, safety, effectiveness and efficacy of protocol driven care among the CIPs. ${ }^{[10,12]}$

Implementation of protocols by nursing staff has become more common, because they ensure consistency of care with cost-conscious appeal, in insulin therapy, ${ }^{[15-18]}$ weaning, ${ }^{[19]}$ pain, agitation and delirium, ${ }^{[20]}$ tube feeding, ${ }^{[21]}$ early progressive mobility, ${ }^{[22]}$ heparin infusion, ${ }^{[23]}$ and other care bundles. [24-29]

Nurses driven electrolytes repletion protocol has several potential advantages; continuous availability of the nurses at patients' bedside, the nurses are more familiar than other health care providers with patients' characteristics and responses. Moreover, nurses have experience and receive training in titrating doses of infused medications, and able than other providers to respond proactively to a patient's rapidly changing needs. This approach increases nurses' autonomy; a concept that has been associated with increasing their perceptions of improved quality of care and job satisfaction. ${ }^{[30,31]}$ Hence, this study was carried out to determine the efficacy of applying nurses driven electrolytes repletion protocol in its ideal situation on electrolytes disturbance control among the CIPs in busy high workload.

\section{MATERIALS AND METHOD}

\subsection{Design}

A quasi-experimental research design was used to conduct this study.

\subsection{Setting}

This study was conducted in 3 medical/surgical ICUs of the Alexandria Main University teaching hospital; casualty care unit (unit I, 8 beds), general II ( 8 beds) and unit III (16 beds) during the period from March 2017 till November 2017. Alexandria Main University Hospitals are a major adult urban teaching, primary and tertiary care facility with 1,900 beds affiliated with a university medical and nursing school, serving 3 governorates (Alexandria, Matrouh, and Behera) with annual admissions more than 10,000 per year.
There is a high workload and turnover especially in ICUs with physician and nursing shortage (ICU physician care for 7-10 CIPs with additional outreach services, ICU nurse care for 1-3 CIPs). In addition, reporting of laboratory values is done through paperwork from central laboratory. There is an axillary pharmacy available for critical care units with bedside preparation of medication including electrolytes.

\subsection{Subjects}

A convenience sample of 62 newly admitted critically ill adult patients (18-60 years) who have electrolytes disturbances has been enrolled as indicated by power analysis using Epi Info 7 program (population size 165 for 3 months, expected frequency $50 \%$, accepted error $10 \%$ and confidence coefficient 99\%). Patients who had renal disorder (serum creatinine $>1.5 \mathrm{mg} / \mathrm{dL}$, urine output $<0.5 \mathrm{ml} / \mathrm{kg} / \mathrm{hr}$, or on any type of renal replacement therapy) or those with diabetic ketoacidosis were excluded from this study.

Patients who had electrolyte disturbances (defined as potassium $<4 \mathrm{mg} / \mathrm{dL}$, magnesium $<2 \mathrm{mg} / \mathrm{dL}$, or phosphorus $<2.5$ $\mathrm{mg} / \mathrm{dL}$ ) were randomly (according to admission; 1st control, 2nd intervention etc.) and equally assigned to either of control or study group (31 patients in each). The control group was managed by unit routine replacement interventions (resident rounding and order written), while the study group were managed by Nurses Driven Electrolytes Repletion Protocol (NDERP) after the written approval of the treating physicians. This protocol was adapted collaboratively from electrolyte replacement practice management guideline that was initially developed by May 2010 ${ }^{[32]}$ at Vanderbilt University and it was reviewed by a jury of five experts in the fields of critical care nursing (one critical care nurse and one critical care nursing academic staff), critical care medicine (One critical care medicine physician and one critical care medicine academic staff), and clinical pharmacy (One clinical pharmacist specialized in critical care) in our university and necessary modifications have been done.

\subsection{Tool}

One tool was used to collect the data of this study namely "Electrolytes repletion assessment record". This tool was developed by the researcher after reviewing the relevant literature. ${ }^{[1,13,33,34]}$ It was used to assess the effect of applying unit routine electrolytes replacement interventions and nurses driven electrolytes repletion protocol on electrolyte disturbances control. It consists of two parts:

Part I: Critically ill patient clinical profile: This part was used to assess the patients' clinical status such as health history, diagnosis of admission, severity of illness using APACHE II scoring system, the use of mechanical ventila- 
tion, fluid balance, length of ICU stay and routine laboratory data as serum creatinine and blood glucose level. In addition, patient demographic data as age and sex were assessed.

Part II: Electrolytes monitoring record: This part was designed to record the following: Patients' electrolytes level during their stay in the ICU to monitor the target electrolytes range and the episodes of electrolytes disturbances, frequency of replacement doses indicated but not given and any electrolytes disturbance related adverse events (e.g. cardiac dysrhythmia, muscle weakness, loss of tendon reflexes, ileus, constipation, somnolence, insulin resistance, neuropathy, seizures, tremors and coma). Also, the time interval from identifying low levels of electrolytes to the time replacement was initiated, replacement doses and frequencies and post-replacement levels were recorded.

\subsection{Method}

A pilot study was carried out on $10 \%$ of the total subjects to evaluate the clarity and applicability of the protocol and necessary modifications were done, and the data obtained were excluded from the study. Reliability of the tool was measured using Cronbach Alpha reliability, the reliability coefficients was $r=0.850$ which is acceptable. The nursing staff in Alexandria critical care department depended on fixed staff with variable training experience (not all registered nurses) and rotatory staff (changes every 2 months) with less training experience with overall shortage especially in night shifts. Therefore, our research hypothesis was based on ideal situation (well experienced registered nurse with an acceptable knowledge on electrolytes replacement and strict application of electrolyte replacement protocol) and evaluating its impact on clinical outcome. Replacement was done by the researcher, in collaboration with physicians and nurses using infusion pump under continuous cardiac monitoring. Training sessions were done for both physicians and nurses before implementation in addition to bedside teaching done during replacing electrolytes for nurses.

\subsection{Data collection}

The following data were collected; age, sex, admission diagnosis, Acute Physiology And Chronic Health Evaluation II (APACHE II) score, serum creatinine, serum level of defined electrolytes (potassium, magnesium, and phosphorus) for seven consecutive days in addition to post-replacement level. All episodes of hypokalemia, hypophosphatemia and hypomagnesaemia, in addition to replacement doses and its frequencies and post-replacement levels for both groups were recorded. Also, replacement doses indicated but not given, the time elapsed from identifying low levels of electrolytes to till initiation of replacement, adverse events due to elec- trolytes disturbance (cardiac dysrhythmia, difficult weaning from mechanical ventilation, ileus, constipation and, tremors) were recorded.

Effectiveness of electrolytes repletion protocol was evaluated by assessment of (1) post replacement electrolytes levels, (2) electrolytes replacement doses to achieve target electrolytes level, (3) number of replacement doses indicated but not given, (4) prevalence of electrolytes loss after replacement and (5) electrolytes loss associated adverse events. Timeliness of electrolytes repletion approaches was evaluated by determining the time between laboratory reporting of low serum electrolytes levels and administration of the replacement doses in both groups. Also survey was done at the end of the study to measure the satisfaction of both nurses and doctor to electrolyte replacement protocol. Nurses and physicians were asked to rate their satisfaction with various aspects of NDERP on a scale of 1-5, where 1 represents the least and 5 represents the most satisfied (see Table 6).

\subsection{Ethical considerations}

Permission to conduct the study was obtained from Alexandria University ethical committee before conduction this study. Informed written consent was obtained from each patient or family member before participation in the study. The anonymity and privacy of the patients; confidentiality of data, and the right to refuse to participate in the study was assured. Patient safety was assured during the study as nurses driven protocol was reviewed by a jury of 5 experts in the field of the study, and was implemented by the researcher in collaboration with resident physicians and nurses using infusion pump under continuous cardiac monitoring.

\subsection{Statistical analysis}

The SPSS Version 20.0 IBM (New York, United States) was used for the analysis of the data. Reliability of the tool was determined by Cronbach alpha. Frequency tables and cross tabulations were used to illustrate the results of categorical data and tested by the Chi Square Test or Fisher's Exact Test. Quantitative data were summarized by the arithmetic mean and standard deviation. Comparison of means was done by Student $t$-test.

\section{RESULTS}

Four hundred thirty two patients were screened and Sixty two newly admitted patients with electrolyte depletion were enrolled in this study after excluding patients with diabetic ketoacidosis and those with renal impairment. One patient developed renal impairment during the study in the control group and another one in the study group; both were excluded from the study. There was a non-significant dif- 
ference between the control and the intervention group as regard age, sex, admission diagnosis, APACHE II score, estimated mortality, serum creatinine as shown in Table 1. The post-replacement electrolyte levels (potassium, magnesium, phosphorus) did not differ significantly between the control and intervention group in the first day of admission, whereas there was a highly significant differences in the following days as shown in Table 2.

Table 1. Comparison between Control and intervention groups according to different parameters

\begin{tabular}{|c|c|c|c|}
\hline & Control $(n=31)$ & Intervention $(n=31)$ & $p$ \\
\hline \multicolumn{4}{|l|}{ Sex } \\
\hline Male $(\%)$ & $22(71 \%)$ & $21(68 \%)$ & \multirow{2}{*}{.782} \\
\hline Female $(\%)$ & $9(29 \%)$ & $10(32 \%)$ & \\
\hline Age Mean \pm SD & $49.9 \pm 13.2$ & $52.0 \pm 14.5$ & .382 \\
\hline \multicolumn{4}{|l|}{ Diagnosis type (\%) } \\
\hline Trauma & $3(9.7 \%)$ & $6(19.4 \%)$ & \multirow{7}{*}{.335} \\
\hline Cardiac & $3(9.7 \%)$ & $5(16.1 \%)$ & \\
\hline Respiratory & $6(19.4 \%)$ & $1(3.2 \%)$ & \\
\hline Surgical & $1(3.2 \%)$ & $1(3.2 \%)$ & \\
\hline Neurological & $14(45.2 \%)$ & $15(48.4 \%)$ & \\
\hline Sepsis & $2(6.5 \%)$ & $2(6.5 \%)$ & \\
\hline Toxicological & $2(6.5 \%)$ & $1(3.2 \%)$ & \\
\hline APACHE score Mean \pm SD & $15.61 \pm 5.85$ & $17.61 \pm 5.68$ & .178 \\
\hline Estimated mortality Mean \pm SD & $25.30 \pm 15.93$ & $30.84 \pm 15.67$ & .173 \\
\hline Serum creatinine Mean \pm SD & $0.56 \pm 0.24$ & $0.52 \pm 0.25$ & .543 \\
\hline \multicolumn{4}{|c|}{ Adverse events for Electrolyte loss (\%) } \\
\hline Dysrhythmia & $53(24.5 \%)$ & $24(11 \%)$ & $<.001 *$ \\
\hline Tremors & $7(3 \%)$ & $5(2.5 \%)$ & .558 \\
\hline Ileus & $24(11 \%)$ & $7(3 \%)$ & $.001 *$ \\
\hline Weaning failure & $18(8.5 \%)$ & $5(2.5 \%)$ & $.005^{*}$ \\
\hline MV days Mean \pm SD & $19.22 \pm 8.12$ & $15.12 \pm 4.95$ & $.020 *$ \\
\hline ICU stay Mean \pm SD & $18.80 \pm 6.20$ & $14.61 \pm 3.91$ & $.002 *$ \\
\hline \multicolumn{4}{|l|}{ Outcome (\%) } \\
\hline Death & $9(29 \%)$ & $5(16 \%)$ & \multirow{2}{*}{.224} \\
\hline Discharge & $22(71 \%)$ & $26(84 \%)$ & \\
\hline \multicolumn{4}{|c|}{ Number of replacement doses indicated but not given (\%) } \\
\hline Potassium & $87 / 181(48 \%)$ & $0 / 100$ & $<.001 *$ \\
\hline Magnesium & $80 / 142(56 \%)$ & $0 / 55$ & $<.001 *$ \\
\hline Phosphorus & $34 / 86(39 \%)$ & $0 / 27$ & $<.001 *$ \\
\hline
\end{tabular}

*: Statistically significant at $p \leq .05$

Table 2. Comparison between the study and the control groups according to the post replacement defined electrolytes level

\begin{tabular}{|c|c|c|c|c|c|c|c|c|c|}
\hline \multirow[b]{2}{*}{ Days } & \multicolumn{2}{|c|}{ Potassium (Mean \pm SD) } & \multirow[b]{2}{*}{$p$} & \multicolumn{2}{|c|}{ Magnesium (Mean \pm SD) } & \multirow[b]{2}{*}{$p$} & \multicolumn{2}{|c|}{ Phosphorus (Mean \pm SD) } & \multirow[b]{2}{*}{$p$} \\
\hline & $\begin{array}{l}\text { Control } \\
(\mathrm{n}=31)\end{array}$ & $\begin{array}{l}\text { Study } \\
(\mathrm{n}=31)\end{array}$ & & $\begin{array}{l}\text { Control } \\
(\mathrm{n}=31)\end{array}$ & $\begin{array}{l}\text { Study } \\
(\mathrm{n}=31)\end{array}$ & & $\begin{array}{l}\text { Control } \\
(\mathrm{n}=31)\end{array}$ & $\begin{array}{l}\text { Study } \\
(n=31)\end{array}$ & \\
\hline First & $3.20 \pm 0.22$ & $3.30 \pm 0.13$ & .262 & $1.66 \pm 0.29$ & $1.65 \pm 0.36$ & .939 & $2.24 \pm 0.64$ & $2.38 \pm 0.46$ & .346 \\
\hline Second & $3.38 \pm 0.31$ & $4.04 \pm 0.40$ & $<.001 *$ & $1.58 \pm 0.35$ & $2.06 \pm 0.27$ & $<.001 *$ & $2.40 \pm 0.43$ & $3.04 \pm 0.63$ & $<.001 *$ \\
\hline Third & $3.44 \pm 0.33$ & $4.00 \pm 0.52$ & $<.001 *$ & $1.70 \pm 0.26$ & $2.17 \pm 0.21$ & $<.001 *$ & $2.53 \pm 0.51$ & $3.25 \pm 0.71$ & $<.001 *$ \\
\hline Fourth & $3.66 \pm 0.39$ & $4.00 \pm 0.34$ & $<.001 *$ & $1.81 \pm 0.33$ & $2.20 \pm 0.27$ & $<.001^{*}$ & $2.49 \pm 0.50$ & $3.14 \pm 0.49$ & $<.001 *$ \\
\hline Fifth & $3.60 \pm 0.43$ & $4.00 \pm 0.45$ & $.001 *$ & $1.81 \pm 0.34$ & $2.12 \pm 0.26$ & $<.001^{*}$ & $2.67 \pm 0.44$ & $3.13 \pm 0.55$ & $<.001 *$ \\
\hline Sixth & $3.77 \pm 0.44$ & $4.00 \pm 0.31$ & $.025 *$ & $1.83 \pm 0.31$ & $2.12 \pm 0.29$ & $<.001^{*}$ & $2.87 \pm 0.47$ & $3.33 \pm 0.62$ & $.002 *$ \\
\hline Seventh & $3.65 \pm 0.35$ & $4.01 \pm 0.24$ & $<.001 *$ & $1.90 \pm 0.23$ & $2.13 \pm 0.29$ & $.002 *$ & $2.95 \pm 0.53$ & $3.35 \pm 0.64$ & $.012 *$ \\
\hline Total & $24.83 \pm 1.14$ & $27.32 \pm 1.24$ & $<.001 *$ & $12.32 \pm 1.35$ & $14.48 \pm 1.18$ & $<.001 *$ & $18.19 \pm 2.32$ & $21.65 \pm 2.75$ & $<.001 *$ \\
\hline
\end{tabular}

*: Statistically significant at $p \leq .05$ 
The total daily replacement doses prescribed for potassium depletion varied between the intervention and the control group. It was non-significantly higher in the control group than in the intervention group in the first day, but it was significantly higher in the following days as shown in Table 3. The total daily replacement doses prescribed for magnesium and phosphorus varied insignificantly between the intervention and control group in the seven days except for the magnesium replacement doses in the first day which was significantly higher in the intervention group as shown in Table 3. The number of replacement doses indicated but not given for hypokalemia, hypomagnesaemia and hypophosphatemia were significantly higher in the control group as compared to the intervention group as shown in Table 1.

Table 3. Comparison between the study and the control groups according to defined electrolytes total daily replacement doses

\begin{tabular}{|c|c|c|c|c|c|c|c|c|c|}
\hline \multirow{2}{*}{ Days } & \multicolumn{2}{|c|}{$\begin{array}{l}\text { Potassium (meq) } \\
\text { Mean } \pm \text { SD }\end{array}$} & \multirow{2}{*}{$p$} & \multicolumn{2}{|c|}{$\begin{array}{l}\text { Magnesium (g) } \\
\text { Mean } \pm \text { SD }\end{array}$} & \multirow{2}{*}{$p$} & \multicolumn{2}{|c|}{$\begin{array}{l}\text { Phosphorus (mmol) } \\
\text { Mean } \pm \text { SD }\end{array}$} & \multirow[b]{2}{*}{$p$} \\
\hline & $\begin{array}{l}\text { Control } \\
(\mathrm{n}=31)\end{array}$ & $\begin{array}{l}\text { Study } \\
(n=31)\end{array}$ & & $\begin{array}{l}\text { Control } \\
(n=31)\end{array}$ & $\begin{array}{l}\text { Study } \\
(n=31)\end{array}$ & & $\begin{array}{l}\text { Control } \\
(n=31)\end{array}$ & $\begin{array}{l}\text { Study } \\
(n=31)\end{array}$ & \\
\hline First & $50.00 \pm 16.80$ & $43.87 \pm 8.08$ & .091 & $2.00 \pm 0.00$ & $3.16 \pm 1.55$ & $.025^{*}$ & $22.22 \pm 6.66$ & $26.15 \pm 6.50$ & .183 \\
\hline Second & $72.77 \pm 22.95$ & $41.17 \pm 4.85$ & $<.001^{*}$ & $2.00 \pm 0.00$ & $2.22 \pm 0.66$ & .281 & $20.00 \pm 0.00$ & $26.66 \pm 11.54$ & .286 \\
\hline Third & $60.66 \pm 24.04$ & $42.66 \pm 10.32$ & $.013 *$ & $2.20 \pm 0.39$ & $2.00 \pm 0.00$ & .322 & $20.00 \pm 0.00$ & $30.00 \pm 14.14$ & .178 \\
\hline Fourth & $64.44 \pm 23.51$ & $42.00 \pm 6.32$ & $.010 *$ & $2.13 \pm 0.23$ & $2.00 \pm 0.00$ & .221 & $25.00 \pm 10.00$ & $20.00 \pm 0.00$ & .685 \\
\hline Fifth & $76.36 \pm 18.04$ & $42.22 \pm 6.66$ & $<.001^{*}$ & $2.21 \pm 0.26$ & $2.00 \pm 0.00$ & .108 & $22.50 \pm 5.00$ & $20.00 \pm 0.00$ & .541 \\
\hline Sixth & $67.00 \pm 18.88$ & $44.44 \pm 8.81$ & $.005 *$ & $2.07 \pm 0.53$ & $2.50 \pm 1.00$ & .369 & $23.33 \pm 5.77$ & $20.00 \pm 0.00$ & .667 \\
\hline Seventh & $74.00 \pm 17.76$ & $42.22 \pm 6.66$ & $<.001^{*}$ & $2.20 \pm 0.27$ & $2.50 \pm 1.00$ & .536 & $25.00 \pm 5.77$ & $20.00 \pm 0.00$ & .495 \\
\hline Total & $191.93 \pm 89.38$ & $138.06 \pm 64.77$ & $.009 *$ & $4.29 \pm 3.92$ & $4.64 \pm 3.97$ & .725 & $23.22 \pm 24.21$ & $18.70 \pm 25.39$ & .483 \\
\hline
\end{tabular}

*: Statistically significant at $p \leq .05$.

The prevalence of hypokalemia, hypomagnesaemia, and hypophosphatemia were significantly higher in the control group from the second till the seventh day with the exception of prevalence of hypophosphatemia were only significantly higher from the second till the fourth day only (see Table
4). The time interval from laboratory reporting of low electrolyte level till initiation of replacement doses was significantly lower in the intervention group in all seven days and all defined electrolytes (see Table 5).

Table 4. Comparison between the study and the control groups according to the prevalence of defined electrolyte imbalance

\begin{tabular}{|c|c|c|c|c|c|c|c|c|c|}
\hline \multirow[b]{2}{*}{ Days } & \multicolumn{2}{|c|}{ Hypokalemia } & \multirow[b]{2}{*}{$p$} & \multicolumn{2}{|c|}{ Hypomagnesaemia } & \multirow[b]{2}{*}{$p$} & \multicolumn{2}{|c|}{ Hypophosphatemia } & \multirow[b]{2}{*}{$p$} \\
\hline & $\begin{array}{l}\text { Control } \\
(n=31)\end{array}$ & $\begin{array}{l}\text { Study } \\
(n=31)\end{array}$ & & $\begin{array}{l}\text { Control } \\
(n=31)\end{array}$ & $\begin{array}{l}\text { Study } \\
(n=31)\end{array}$ & & $\begin{array}{l}\text { Control } \\
(n=31)\end{array}$ & $\begin{array}{l}\text { Study } \\
(\mathrm{n}=31)\end{array}$ & \\
\hline First & $31(100 \%)$ & $31(100 \%)$ & NA & $23(74 \%)$ & $24(77 \%)$ & 0.766 & $17(55 \%)$ & $17(55 \%)$ & 1.000 \\
\hline Second & $26(84 \%)$ & $17(55 \%)$ & $.013 *$ & $25(81 \%)$ & $9(29 \%)$ & $<.001 *$ & $14(45 \%)$ & $3(10 \%)$ & $.001 *$ \\
\hline Third & $28(90 \%)$ & $15(48 \%)$ & $<.001 *$ & $24(77 \%)$ & $4(13 \%)$ & $<.001^{*}$ & $12(39 \%)$ & $2(6 \%)$ & $.002 *$ \\
\hline Fourth & $25(81 \%)$ & $10(32 \%)$ & $<.001 *$ & $21(68 \%)$ & $5(16 \%)$ & $<.001^{*}$ & $11(35 \%)$ & $1(3 \%)$ & $.001 *$ \\
\hline Fifth & $25(81 \%)$ & $9(29 \%)$ & $<.001^{*}$ & $16(52 \%)$ & $5(16 \%)$ & $.003 *$ & $7(23 \%)$ & $2(6 \%)$ & .071 \\
\hline Sixth & $22(71 \%)$ & $9(29 \%)$ & $.002 *$ & $16(52 \%)$ & $4(13 \%)$ & $.001 *$ & $3(10 \%)$ & $1(3 \%)$ & .307 \\
\hline Seventh & $24(77 \%)$ & $9(29 \%)$ & $<.001 *$ & $17(55 \%)$ & $4(13 \%)$ & $<.001 *$ & $4(13 \%)$ & $1(3 \%)$ & .166 \\
\hline
\end{tabular}

NA: Test is not applicable; *: Statistically significant at $p \leq .05$

As regard patient outcome, the electrolyte depletion related adverse events differed between both groups. The incidence of dysrhythmia, ileus and weaning failure were significantly lower in the study group, whereas the incidence of tremors did not reach statistical significance (see Table 1). Consequently, there were significantly decreased mechanical venti- lation and ICU days without significant change of mortality rate in the intervention group as compared to the control group (see Table 1). The results of nurses and physicians survey about the satisfaction of nurse driven electrolyte replacement protocol are shown in Table 6. 
Table 5. Comparison between the study and the control group according to timing of defined electrolyte replacements (in minutes)

\begin{tabular}{|c|c|c|c|c|c|c|c|c|c|}
\hline \multirow[b]{2}{*}{ Days } & \multicolumn{2}{|c|}{ Potassium (Mean \pm SD) } & \multirow[b]{2}{*}{$p$} & \multicolumn{2}{|c|}{ Magnesium (Mean \pm SD) } & \multirow[b]{2}{*}{$p$} & \multicolumn{2}{|c|}{ Phosphorus (Mean \pm SD) } & \multirow[b]{2}{*}{$p$} \\
\hline & $\begin{array}{l}\text { Control } \\
(\mathrm{n}=31)\end{array}$ & $\begin{array}{l}\text { Study } \\
(\mathrm{n}=31)\end{array}$ & & $\begin{array}{l}\text { Control } \\
(\mathrm{n}=31)\end{array}$ & $\begin{array}{l}\text { Study } \\
(n=31)\end{array}$ & & $\begin{array}{l}\text { Control } \\
(\mathrm{n}=31)\end{array}$ & $\begin{array}{l}\text { Study } \\
(n=31)\end{array}$ & \\
\hline First & $193.3 \pm 115.6$ & $30.3 \pm 0$ & $.000 *$ & $258 \pm 192.8$ & $32.5 \pm 13.9$ & $.000^{*}$ & $246.7 \pm 70$ & $42.3 \pm 36.5$ & $.000 *$ \\
\hline Second & $200 \pm 100.8$ & $42.4 \pm 15.2$ & $.000 *$ & $229.1 \pm 58.9$ & $53.3 \pm 39.3$ & $.000 *$ & $285 \pm 90$ & $33.3 \pm 5.8$ & $.000 *$ \\
\hline Third & $190.3 \pm 124.6$ & $39.3 \pm 10.3$ & $.000 *$ & $256.7 \pm 122.9$ & $30 \pm 8.16$ & $.000 *$ & $210 \pm 34.6$ & $25 \pm 7.1$ & $.000 *$ \\
\hline Fourth & $173.3 \pm 101.5$ & $26 \pm 7$ & $.000 *$ & $250.9 \pm 92.2$ & $28.00 \pm 8.36$ & $.000 *$ & $255 \pm 75.5$ & $20 \pm 0$ & $.000 *$ \\
\hline Fifth & $228 \pm 101.2$ & $30 \pm 5$ & $.000 *$ & $231.4 \pm 72.9$ & $30.1 \pm 10$ & $.000 *$ & $225 \pm 142.1$ & $35 \pm 7.1$ & $.000 *$ \\
\hline Sixth & $270 \pm 86$ & $36.1 \pm 18.7$ & $.000 *$ & $197.1 \pm 66.8$ & $25 \pm 5.8$ & $.000 *$ & $260 \pm 91.7$ & $30 \pm 0$ & $.000 *$ \\
\hline Seventh & $228 \pm 61.9$ & $30 \pm 7.1$ & $.000 *$ & $288 \pm 98.6$ & $30 \pm 8.16$ & $.000 *$ & $220 \pm 109.5$ & $20 \pm 0$ & $.000 *$ \\
\hline Total & $606.5 \pm 340.9$ & $108.5 \pm 52.6$ & $.000 *$ & $496.1 \pm 474.6$ & $60.9 \pm 54.7$ & $.000^{*}$ & $250.9 \pm 264.2$ & $27.1 \pm 40.2$ & $.000 *$ \\
\hline
\end{tabular}

*: Statistically significant at $p \leq .05$

Table 6. Nurse driven electrolyte replacement satisfaction survey among critical care staff

\begin{tabular}{|c|c|c|}
\hline \multirow{2}{*}{ Questions } & Nurses $(n=48)$ & Physicians $(n=48)$ \\
\hline & Mean \pm SD & Mean \pm SD \\
\hline $\begin{array}{l}\text { 1. How would you rate your satisfaction with the overall effectiveness of our } \\
\text { Electrolyte Replacement Protocol? }\end{array}$ & $4.3 \pm 0.9$ & $4.0 \pm 0.5$ \\
\hline $\begin{array}{l}\text { 2. How would you rate your satisfaction with the adequacy of electrolyte replacement } \\
\text { achieved with the Electrolyte Replacement Protocol? }\end{array}$ & $4.3 \pm 0.9$ & $4.1 \pm 0.4$ \\
\hline $\begin{array}{l}\text { 3. How would you rate your satisfaction with the timeliness of electrolyte } \\
\text { replacement achieved with the Electrolyte Replacement Protocol? }\end{array}$ & $4.6 \pm 0.7$ & $4.1 \pm 0.9$ \\
\hline \multicolumn{3}{|l|}{ 4. How would you rate your overall satisfaction with } \\
\hline \multirow{2}{*}{$\begin{array}{l}\text { a. Number of levels done } \\
\text { b. The lack of need to seek orders for replacement doses (nurses), the decrease in } \\
\text { requests for electrolyte replacement orders (physicians) }\end{array}$} & $3.9 \pm 1.2$ & $3.2 \pm 1.1$ \\
\hline & $4.7 \pm 0.7$ & $4.8 \pm 0.4$ \\
\hline $\begin{array}{l}\text { c. Knowing when to repeat levels after replacement is given (nurses), timing of } \\
\text { repeat levels after replacement is given (physicians) }\end{array}$ & $4.8 \pm 0.7$ & $3.8 \pm 1.1$ \\
\hline d. Nursing autonomy to replace electrolytes per protocol & $4.6 \pm 0.6$ & $4.9 \pm 0.3$ \\
\hline $\begin{array}{l}\text { 5. How useful do you think the Electrolyte Replacement Protocol has been in patient } \\
\text { management? }\end{array}$ & $4.5 \pm 0.7$ & $4.1 \pm 0.8$ \\
\hline $\begin{array}{l}\text { 6. How useful do you feel that the Electrolyte Replacement Protocol has been to your } \\
\text { practice as a nurse/physician? }\end{array}$ & $4.4 \pm 0.9$ & $4.3 \pm 0.5$ \\
\hline
\end{tabular}

\section{Discussion}

Electrolytes disturbances affect the outcomes of the CIPs through their crucial role in maintaining the hemostasis of their body's functions. Many of these disturbances are a result of critical illness combined with therapies adopted by critical care team. Protocolized directed therapies in ICUs have been demonstrated positive clinical outcomes in mechanical ventilation, sedation, glycemic control and mobility. ${ }^{[15,17-20]}$ Thus, protocolization of electrolyte repletion and driving it by nurses may ensure timely, safe and effective care. Therefore, this study was conducted to determine the effect of implementing nurses driven electrolytes repletion protocol (NDERP) on electrolytes disturbances control among critically ill patients.

Published by Sciedu Press

The main results of the study revealed that implementation of nurses driven electrolytes repletion protocol among CIPs resulted in improvements in the effectiveness (postreplacement levels were higher with lower replacement doses and lower incidence of electrolyte depletion) and timeliness (less time for electrolyte repletion and to reach target level) of electrolyte replacement. These findings comes in accordance with by Kanji and Jung (2009), ${ }^{[35]}$ Todd et al. (2009), ${ }^{[36]}$ and Hijazi and Al-Ansari (2005). ${ }^{[13]}$

As regard the effectiveness of electrolytes protocol, first, the mean potassium level did not differ between the study and the control group in the first day without difference in the replacement doses, but there was a highly statistical differ- 
ence throughout the following sixth consecutive days and in the total mean of potassium level with significantly lower replacement doses in the study group. Moreover, patients in the study group have achieved the target potassium level (4-5) $\mathrm{mEq} / \mathrm{dl}$ from the second day of the study in contrary with patients in the control group who have not achieved this target level throughout the seven consecutive days of the study. Consequently, the incidence of hypokalemia was significantly lower in the study group from the second day to the seventh day of the study.

This was the same as Amirnovin et al. (2018), ${ }^{[37]}$ Johnston et al. (2017) ${ }^{[38]}$ Scotto et al. (2014), ${ }^{[39]}$ Couture et al. (2013), ${ }^{[33]}$ Kanji and Jung (2009) ${ }^{[35]}$ Owen et al. $(2008)^{[40]}$ and Hijazi and Al-Ansari (2005) ${ }^{[13]}$ findings. On the other hand, Zielenski et al. (2017) ${ }^{[41]}$ reported that timed, electronic, assessment-driven potassium-replacement protocol (TARP) improved the effectiveness and safety of potassiumreplacement therapy over the traditional NDERP without negatively affecting timeliness of care.

This may be attributed to replacement strategy in the study group that depends on prevention (target serum potassium $\geq$ $4 \mathrm{meq} / \mathrm{dl}$ ) rather than treatment in the control group (serum potassium $<3.5 \mathrm{meq} / \mathrm{dl}$ ). Thus, repletion based on prevention rather than treatment in the study group was more effective; lower repletion doses in a decreasing trend throughout the seven days of the study with achievement of target levels timely when compared to the control group. Moreover, timeliness of potassium repletion helps in controlling the loss early that makes repletion easy with lower doses of potassium chloride than late one which will become refractory to repletion. This was evident in the control group as there were increasing potassium replacement doses from (50.00 $\pm 16.80) \mathrm{mEq}$ in the first day to $(74.00 \pm 17.76) \mathrm{mEq}$ in the seventh day without achieving adequate potassium level throughout the seven days.

This is nearly in line with the findings of a retrospective large data base study that was conducted by Joseph et al. (2018). ${ }^{[42]}$ Another possible interpretation was coordinated and timely repletion of magnesium in the study group that is essential for potassium hemostasis. The prevalence of hypomagnesaemia among the control group was high when compared with the study group.

Second, the mean magnesium level did not differ in the first day between the two groups with significantly higher replacement doses in the study group. On the contrary, it was significantly higher in the study group throughout the following sixth consecutive days and in the total mean magnesium level without significant differences in the replacement doses. Moreover, patients in the study group have achieved the tar- get magnesium level (2-2.7) $\mathrm{mg} / \mathrm{dl}$ from the second day of the study in contrary of patients in the control group who have not achieved this target level throughout the seven consecutive days of the study. Consequently, the incidence of hypomagnesaemia was significantly lower in the study group from the second day to the seventh day of the study.

This is in accordance with Hammond et al. (2017), ${ }^{[43]}$ Kanji and Jung (2009), ${ }^{[35]}$ Owen et al. (2008) $)^{[40]}$ and Hijazi and Al-Ansari (2005) ${ }^{[13]}$ findings. On the country, Couture et al. $(2013)^{[33]}$ did not find difference between the two groups in relation to magnesium replacement.

This may be related to repletion strategy in the study group that depends on prevention (serum magnesium $\geq 2 \mathrm{mg} / \mathrm{dl}$ ) rather than treatment (serum magnesium level $<1.5 \mathrm{mg} / \mathrm{dl}$ ) in the control group. So that, repletion doses of magnesium in a decreasing trend throughout the seven days of the study with achievement of target levels timely when compared to the control group. Additionally, doses that have been used in the control group are inadequate and mostly fixed for all types of hypomagnesaemia ( 2 gram of magnesium sulfate). Moreover, earlier management of magnesium losses is easier than late one which will become refractory to repletion. However the difference between the study and control group did not reach statistical significance.

This is nearly in line with the findings of a retrospective large data base study that was conducted by Joseph et al. (2018). ${ }^{[42]}$ Another possible interpretation was coordinated and timely repletion of phosphate in the study group that is essential in magnesium hemostasis. The prevalence of hypophosphatemia among the control group was high when compared with the study group.

Finally, the mean phosphorus level did not differ significantly in the first day between the two groups without significant difference between replacement doses. On the contrary, the mean phosphorus level was significantly higher in the study group throughout the following sixth consecutive days and in the total mean phosphorus level with insignificant difference in the replacement doses between both groups. Moreover, patients in the study group have achieved the target phosphorus level (2.5-4.5) $\mathrm{mg} / \mathrm{dl}$ from the second day of the study. In contrary of patients in the control group who have achieved this target level on the third day of the study followed by a drop in the fourth day then achieved again in the fifth day study to the seventh day. Consequently, there was significant decrease of incidence of hypophosphatemia in the study group from the second day to the fourth day of the study.

This is in accordance with Kanji and Jung (2009), ${ }^{[35]}$ Brwon et al. (2006), ${ }^{[44]}$ Hijazi and Al-Ansari (2005) ${ }^{[13]}$ and Tay- 
lor et al. (2004). ${ }^{[45]}$ However, Couture et al. (2013) ${ }^{[33]}$ and Owen et al. (2008) ${ }^{[40]}$ found no statistical difference between the two groups in relation to phosphorus replacement suggesting an increase in replacement doses in study group to be more effective in the management of hypophosphatemia from the second day to the fourth day of the study.

This may be imputed to repletion strategy in the study group that depends on prevention (serum phosphorus $\geq 2.5 \mathrm{mg} / \mathrm{dl}$ ) rather than treatment (Serum phosphorus $<1.8 \mathrm{mg} / \mathrm{dl}$ ) in the control group. So that, repletion doses of medications in a decreasing trend throughout the seven days of the study with achievement of target levels timely when compared to the control group. Additionally, doses that have been used in the control group are inadequate and mostly fixed for all types of hypophosphatemia ( $20 \mathrm{mmol}$ of sodium phosphate). However, replacement doses between both groups did not reach statistical significance. Moreover, earlier management of phosphate loss is easier in the study group than late one which will become refractory to repletion.

This is nearly in line with the findings of a retrospective large data base study that was conducted by Joseph et al. (2018). ${ }^{[42]}$ It may be related to continuous monitoring and timely repletion of electrolytes losses according to NDERP that focus on prevention rather than treatment. Also, coordinated replacement of electrolytes helps in achievement of effective timely control; for example: hypomagnesaemia was corrected before hypokalemia as magnesium is essential for potassium hemostasis. Early repletion makes the management of electrolytes loss easier than late one.

In relation to, the number of potassium, magnesium and phosphorus replacement doses indicated but not given among the studied CIPs, there was a highly significant decrease in the study group (zero) as compared to the control group. This in accordance to Kanji et al. ${ }^{[35]}$ In this study, an experienced nurse (the researcher) was assigned for electrolyte replacement with strict application of protocol, this explain why there was no missed doses.

About timeliness of electrolytes repletion, the total mean timing for potassium, magnesium and phosphorus replacement were significantly lower in the study group. This is in accordance with Pearson et al. (2016), ${ }^{[14]}$ Kanji and Jung (2009 and Amirnovin et al. (2018). ${ }^{[37]}$ It may be related to summarizing the reporting process steps as repletion started once electrolytes loss were identified by bedside nurses. Furthermore, increased nurse's awareness, knowledge and eagerness about electrolytes repletion facilitate its' performance while caring for the CIPs that ensures continued monitoring and timely effective action.
Regarding adverse events associated with electrolytes depletion, the incidence of dysrhythmia, ileus and weaning failure were significantly reduced in the study group as compared to the control group. On the other hand, the incidence of tremors reduced insignificantly in the study group. Furthermore, MV and ICU days decreased significantly in the study group with insignificant change of mortality rates. In contrary to this, Hoekstra et al. ${ }^{[34]}$ who implemented computerized potassium protocol, reported non-significant change of ICU days or mortality rate with this protocol. Up to our knowledge, no other NDERP evaluated clinical outcomes.

The survey showed satisfaction of ICU staff especially nurses to NDERP as shown in Kanji et al study. ${ }^{[35]}$ The timeliness of NDERP, the lack of need to seek orders for replacement doses (nurses), the decrease in requests for electrolyte replacement orders (physicians), the knowledge when to repeat levels after replacement is given (nurses), and the nursing autonomy were among the highest rated items. Both physicians and nurse believed in the usefulness and effectiveness of NDERP in their own practice.

To summarize, NDERP have shown effectiveness in terms of achieving target electrolytes levels with lower replacement doses and lower incidence of electrolytes disturbances from the second day, its adverse events and missed doses. Also its timeliness was shown in earlier initiation of repletion and timely achievement of target electrolytes levels from the second day. Cost effectiveness is clearly obvious from low costs of this protocol (paper printing) in face of costs of additional replacement doses, more attacks of dysrhythmia, and more MV and ICU days.

All this may be imputed to the busy and dynamic nature of ICU environment, in which intensivists makes numerous decisions everyday as regard patient care. One aspect of these decisions was related to electrolytes management, in which nurses only administer the drugs ordered for replacement. The highly work loaded intensivists who works in singular base not in interdisciplinary approach will miss some decisions or make them late that affects the quality of patients care negatively. It is worth mentioning that this practice of administration usually not based on recent clinical practice guidelines recommendations that make it unsafe. ${ }^{[14,33]}$

Nurse's knowledge and practice for this crucial issue are lacking. Furthermore, nurses have no active role in ordering, reporting, and initiating and terminating electrolytes repletion. Thus, late reporting, inadequate doses, non-uniformed and uncoordinated unsafe late repletion make the practice of electrolytes repletion inadequate, ineffective, unsafe and not timely. So, active participation of nurses in NDERP and their eagerness to learn this new skill help in terminating 
any missed repletion doses in the study group that ultimately maximizes the effectiveness, adequacy, timeliness and safety of NDERP. The new assignment converts most of them form reluctant workers to active champion at bedside. ${ }^{[13,37]}$

Most of the results of this study were highly significant compared to previous studies and this might be attributed to several factors. First, we studied the impact of ideal situation including experienced nurse, high knowledge and strict application of NDERP. Second, the control group might have delayed and suboptimal electrolyte repletion as compared to other studies due to our busy ICU and lack of electronic reporting of electrolytes levels. Third, the diversity of intensivists' perception of electrolytes repletion might be a contributing factor.

\subsection{Implication for clinical practice}

- The current study may provide more identification of adverse events associated with electrolytes loss in intensive care units in Alexandria.

- Results were in accordance with previous studies that will help in generalization of the research findings globally and to complete the scene of this important problem.
- Results help in empowerment of nurses as nurses driven protocols were more effective and timely than traditional methods that ensure high quality care.

\subsection{Limitations of the study}

This study was single blinded (blinded to patients not to researchers) which might affected some of subjective variables as diagnosis of ileus. The high impact of NDERP might be specific to our context but agree with other international studies of its effectiveness and timeliness. There might be other confounding factors other than demographic, admission diagnosis, APACHE and serum creatinine which might affected our results especially MV and ICU days and mortality rate.

\section{Conclusion}

The implementation of nurses driven electrolytes repletion protocol among CIPs resulted in improvements in the effectiveness and timeliness of electrolyte replacement with greater clinical impact in units with ICU physicians' shortage with probable less clinical adverse events and less MV and ICU days.

\section{Conflicts OF InTEREST Disclosure}

The authors declare that there is no conflict of interest.

\section{REFERENCES}

[1] Palepu R, Freebairn R. Electrolyte disorders in the critically ill. Anesthesia and Intensive Care Medicine. 2014; 15(2): 79-80. https: //doi.org/10.1016/j.mpaic. 2013.12.004

[2] Rhee P, Joseph B. Shock, Electrolytes, and Fluid. In: Beauchamp D, Evers M, Mattox K, Townsend C, editors. Sabiston Textbook of Surgery E-Book. 20th ed. Philadelphia Elsevier Health Sciences; 2017. p. 86-95.

[3] Kardalas E, Paschou S, Anagnostis P, et al. Hypokalemia: a clinical update. Endocrine Connections. 2018; 7(4): R135-R46. PMid:29540487 https : //doi.org/10.1530/EC-18-0109

[4] Kamel K, Halperin M. Hypokalemia In: Kamel K, Halperin M, editors. Fluid, Electrolyte and Acid-Base Physiology: A Problem-Based Approach. 5th ed. Philadelphia: Elsevier Health Sciences; 2017; 396-427.

[5] Velissaris D, Karamouzos V, Pierrakos C, et al. Hypomagnesemia in critically ill sepsis patients. J Clin Med Res. 2015; 7(12): 911. PMid:26566403 https://doi.org/10.14740/jocmr2351w

[6] Hansen B, Bruserud O. Hypomagnesemia in critically ill patients. Journal of Intensive Care. 2018; 6(1): 21. PMid:29610664 https : //doi.org/10.1186/s40560-018-0291-y

[7] Suzuki S, Egi M, Schneider A, et al. Hypophosphatemia in critically ill patients. J Crit Care. 2013; 28(4): 536. e9-e19. PMid:23265292 https://doi.org/10.1016/j.jcrc.2012.10.011

[8] Zhao Y, Li Z, Shi Y, et al. Effect of hypophosphatemia on the withdrawal of mechanical ventilation in patients with acute exacerbations of chronic obstructive pulmonary disease. Biomedical Reports. 2016;
4(4): 413-6. PMid:27073623 https://doi.org/10.3892/br.2 016.605

[9] Lee J. Fluid and electrolyte disturbances in critically ill patients. Electrolytes \& Blood Pressure. 2010; 8(2): 72-81. PMid:21468200 https://doi.org/10.5049/EBP. 2010.8.2.72

[10] Weled B, Adzhigirey L, Hodgman T, et al. Critical care delivery: the importance of process of care and ICU structure to improved outcomes: an update from the American college of critical care medicine task force on models of critical care. Crit Care Med. 2015; 43(7): 1520-5. PMid:25803647 https ://doi.org/10.1097/CCM. 0000 000000000978

[11] Ali N, Gutteridge D, Shahul S, et al. Critical illness outcome study: an observational study on protocols and mortality in intensive care units. Open Access J Clin Trials. 2011; 1(3): 55. PMid:25429244 https://doi.org/10.2147/OAJCT.S24223

[12] Todd S, Sucher J, Moore L, et al. A multidisciplinary protocol improves electrolyte replacement and its effectiveness. The American Journal of Surgery. 2009; 198(6): 911-5. PMid:19969151 https://doi.org/10.1016/j.amjsurg. 2009.04.032

[13] Hijazi M, Al-Ansari M. Protocol-driven vs. physician-driven electrolyte replacement in adult critically ill patients. Ann Saudi Med. 2005; 25(2): 105-9. PMid:15977686 https://doi.org/10.514 4/0256-4947.2005. 105

[14] Pearson DJ, Sharma A, Lospinoso JA, et al. Effects of Electrolyte Replacement Protocol Implementation in a Medical Intensive Care Unit. Journal of intensive care medicine. 2018; 33(10): 574-81. 
PMid:27881698 https ://doi.org/10.1177/08850666166795 93

[15] Association AD. Standards of medical care in diabetes-2010. Diabetes care. 2010; 33(Supplement 1): S11-S61. PMid:20042772 https://doi.org/10.2337/dc10-S011

[16] Goldberg PA, Siegel MD, Sherwin RS, et al. Implementation of a safe and effective insulin infusion protocol in a medical intensive care unit. Diabetes care. 2004; 27(2): 461-7. PMid:14747229 https://doi.org/10.2337/diacare.27.2.461

[17] Kane J, Coonerty E, Spellman-Foley P. "How Sweet It Is": Taking the Fear Away From Managing Insulin Infusions. Critical Care Nurse. 2016; 36(2). PMid:27694354 https ://doi.org/10.4037/ccn2 016671

[18] Gæde P, Valentine WJ, Palmer AJ, et al. Cost-effectiveness of intensified versus conventional multifactorial intervention in type 2 diabetes: results and projections from the Steno-2 study. Diabetes Care. 2008; 31(8): 1510-5. PMid:18443195 https://doi.org/10.2337/dc 07-2452

[19] Bowles MJ, editor Weaning Protocol for Early Liberation From Mechanical Ventilation. CRITICAL CARE NURSE; 2018: AMER ASSOC CRITICAL CARE NURSES 101 COLUMBIA, ALISO VIEJO, CA 92656 USA.

[20] Mansouri P, Javadpour S, Zand F, et al. Implementation of a protocol for integrated management of pain, agitation, and delirium can improve clinical outcomes in the intensive care unit: a randomized clinical trial. Journal of Critical Care. 2013; 28(6): 918-22. PMid:24011845 https://doi.org/10.1016/j.jcrc. 2013.06 .019

[21] Bell A, Hidalgo D, Medina M, editors. A Collaborative Team-Driven Tube Feeding and Nutrition Consultation Protocol in a Medical Intensive Care Unit. Critical Care Nurse; 2018: AMER ASSOC CRITICAL CARE NURSES 101 COLUMBIA, ALISO VIEJO, CA 92656 USA.

[22] Hiner A, Dougan K. Up and At'em: Creating an Interprofessional Early Progressive Mobility Program for the Critically Ill. Critical Care Nurse. 2017; 37(2): e39-e40.

[23] Schurr JW, Stevens CA, Bane A, et al. Evaluation of Compliance with a Weight-based Nurse-driven Heparin Nomogram in a Tertiary Academic Medical Center. Critical pathways in cardiology. 2018; 17(2): 83-7. PMid:29768316 https://doi .org/10.1097/HPC. 000000 0000000113

[24] Cochran M, Winchester D, Miller K, editors. Medical Intensive Care Unit: Our Catheter-Associated Urinary Tract Infection Journey. Critical Care Nurse; 2018: AMER ASSOC CRITICAL CARE NURSES 101 COLUMBIA, ALISO VIEJO, CA 92656 USA.

[25] Furdyna W, Blystone L, editors. Guided by Why: A Nurseand Respiratory Therapist-Driven Protocol to Decrease VentilatorAssociated Pneumonia in a Medical Intensive Care Unit. Critical Care Nurse; 2018: AMER ASSOC CRITICAL CARE NURSES 101 COLUMBIA, ALISO VIEJO, CA 92656 USA.

[26] Kapoor N, Wilson T, editors. Implementation of a nurse-driven bedside sepsis checklist to improve early, goal-directed therapy. Crit Care Nurse; 2018: American Association of Critical Care Nurses 101 Columbia, Aliso Viejo, CA 92656 USA.

[27] Ryan C, editor REFRESH: Restore Energy for Recovery Encourage Sleep for Healing. Promoting Sleep in the Intensive Care Unit. Critical Care Nurse; 2018: AMER ASSOC CRITICAL CARE NURSES 101 COLUMBIA, ALISO VIEJO, CA 92656 USA.

[28] Adamson S, Rizo K, Katsumoto K. breaking the Fall: Going Above and Beyond the Fall Bundle: eb111. Critical Care Nurse. 2016; 36(2): e50.

Published by Sciedu Press
[29] Adams B, Brohm J, Goolsby J, et al. red-be-gone: Reducing Incontinence-associated Dermatitis in the Intensive Care Unit by Using the Evidence!: eb76. Crit Care Nurse. 2016;36(2): e32-e3.

[30] Chant C, Mustard M, Thorpe KE, et al. Nurse-vs nomogram-directed glucose control in a cardiovascular intensive care unit. American Journal of Critical Care. 2012; 21(4): 270-8. PMid:22751370 https://doi.org/10.4037/ajcc2012713

[31] Casey C, Balas M. Use of Protocols in Older Intensive Care Unit Patients: Is Standardization Appropriate? Advanced Critical Care. 2011; 22(2): 150-60. https://doi.org/10.4037/NCI.0b013e $3182156 \mathrm{cc} 7$

[32] May A. Electrolyte replacement practice management guidline Vanderbilt, 2010 [cited 2016 12th November]. Available from: https://medschool.vanderbilt.edu/trauma-andscc/fi les/trauma-andscc/public_files/Protocols/Electroly te\%20Replacement.pdf

[33] Couture J, Létourneau A, Dubuc A, et al. Evaluation of an Electrolyte Repletion Protocol for Cardiac Surgery Intensive Care Patients. Can J Hosp Pharm. 2013; 66(2): 96-103. PMid:23616673 https://doi.org/10.4212/cjhp.v66i2.1231

[34] Hoekstra M, Vogelzang M, Drost J, et al. Implementation and evaluation of a nurse-centered computerized potassium regulation protocol in the intensive care unit-a before and after analysis. BMC Med Inform Decis Mak. 2010; 10: 5. PMid:20100342 https: //doi.org/10.1186/1472-6947-10-5

[35] Kanji Z, Jung K. Evaluation of an electrolyte replacement protocol in an adult intensive care unit: a retrospective before and after analysis. Intensive Crit Care Nurs. 2009; 25(4): 181-9. PMid:19398203 https://doi.org/10.1016/j.iccn.2009.03.004

[36] Todd S, Sucher J, Moore L, et al. A multidisciplinary protocol improves electrolyte replacement and its effectiveness. The American Journal of Surgery. 2009; 198(6): 911-5. PMid:19969151 https://doi.org/10.1016/j.amjsurg. 2009.04.032

[37] Amirnovin R, Lieu P, Imperial-Perez F, et al. Safety, Efficacy, and Timeliness of Intravenous Potassium Chloride Replacement Protocols in a Pediatric Cardiothoracic Intensive Care Unit. Journal of intensive care medicine. 2018. PMid:29357785 https://doi .or $\mathrm{g} / 10.1177 / 0885066617752659$

[38] Johnston C, Maish III G, Minard G, et al. Evaluation of an intravenous potassium dosing algorithm for hypokalemic critically ill patients. Journal of Parenteral and Enteral Nutrition. 2017; 41(5): 796-804 PMid:26304602 https: //doi.org/10.1177/01486071156028 85

[39] Scotto C, Fridline M, Menhart C, et al. Preventing hypokalemia in critically ill patients. Am J Crit Care. 2014; 23(2): 145-9. PMid:24585163 https://doi .org/10.4037/ajcc2014946

[40] Owen P, Monahan M, MacLaren R. Implementing and assessing an evidence-based electrolyte dosing order form in the medical ICU. Intensive Crit Care Nurs. 2008; 24(1): 8-19. PMid:17686630 https://doi.org/10.1016/j.iccn.2007.04.006

[41] Zielenski C, Crabtree A, Le T, et al. Implementation of a timed, electronic, assessment driven potassium replacement protocol. Am J Health Syst Pharm. 2017; 74(12): 927-31. PMid:28487284 https : //doi.org/10.2146/ajhp160378

[42] Joseph T, Di Meglio M, Huffenberger A, et al. Behavioural patterns of electrolyte repletion in intensive care units: lessons from a large electronic dataset. Sci Rep. 2018; 8(1): 11915. PMid:30093668 https://doi.org/10.1038/s41598-018-30444-3

[43] Hammond D, Stojakovic J, Kathe N, et al. Effectiveness and safety of magnesium replacement in critically ill patients admitted to the medical intensive care unit in an academic medical center: a retrospective, cohort study. J Intensive Care Med. 2017; 1-8. 
[44] Brown K, Dickerson R, Morgan L, et al. A new graduated dosing regimen for phosphorus replacement in patients receiving nutrition support. Journal of Parenteral and Enteral Nutrition. 2006; 30(3): 209-14. PMid:16639067 https://doi.org/10.1177/01486071 06030003209
[45] Taylor B, Huey W, Buchman T, et al. Treatment of hypophosphatemia using a protocol based on patient weight and serum phosphorus level in a surgical intensive care unit. J Am Coll Surg. 2004; 198(2): 198204. PMid:14759775 https://doi.org/10.1016/j.jamcolls urg. 2003.09.013 